\title{
Potential Therapeutic Roles for Direct Factor Xa Inhibitors in Coronavirus Infections
}

\author{
Rami A. Al-Horani ${ }^{1}$ (1)
}

Published online: 12 September 2020

(c) Springer Nature Switzerland AG 2020

\begin{abstract}
Human factor Xa (FXa) is a serine protease of the common coagulation pathway. FXa is known to activate prothrombin to thrombin, which eventually leads to the formation of cross-linked blood clots. While this process is important in maintaining hemostasis, excessive thrombin generation results in a host of thrombotic conditions. FXa has also been linked to inflammation via protease-activated receptors. Together, coagulopathy and inflammation have been implicated in the pathogenesis of viral infections, including the current coronavirus pandemic. Direct FXa inhibitors have been shown to possess anti-inflammatory and antiviral effects, in addition to their established anticoagulant activity. This review summarizes the pharmacological activities of direct FXa inhibitors, their pharmacokinetics, potential drug-drug interactions and adverse effects, and the details of clinical trials involving direct FXa inhibitors in coronavirus disease 2019 (COVID-19) patients.
\end{abstract}

\section{Key Points}

Factor Xa is a serine protease in the common coagulation pathway, the excessive stimulation of which leads to a host of thrombotic conditions.

Factor Xa has also been linked to inflammation as well as viral infections.

In addition to their established anticoagulant properties, factor Xa inhibitors have exhibited significant anti-inflammatory and antiviral effects in several testing settings.

Currently, there are $>10$ clinical trials for evaluating the potential of factor $\mathrm{Xa}$ inhibitors in coronavirus disease 2019 (COVID-19) patients.

Strategies to administer these drugs parenterally may facilitate their use in critically ill COVID-19 patients.

Rami A. Al-Horani

ralhoran@xula.edu

1 Division of Basic Pharmaceutical Sciences, College of Pharmacy, Xavier University of Louisiana, 1 Drexel Drive, New Orleans, LA 70125-1089, USA

\section{Introduction}

The coronavirus disease 2019 (COVID-19) pandemic continues to impact the whole world. Since December 2019, there have been more than 23 million reported confirmed cases worldwide and more than 800 thousand human lives lost to the viral infection and/or its complications [1]. While most patients appear to develop a mild illness, the elderly (>65 years of age) and patients with comorbidities of cardiovascular diseases, diabetes, hypertension, or cancer are at a higher risk of death [2]. Despite recommendations and approvals of compassionate use of few potential therapeutics, no vaccines or highly effective therapeutics are available; however, knowledge pertaining to the virus lifecycle and the disease pathogenesis continues to evolve.

Considering clinical reports, some COVID-19 patients have exhibited a hypercoagulable state, as indicated by the elevated levels of D-dimer and fibrinogen and the prolonged prothrombin time [3]. Furthermore, a number of inflammatory markers have been reported to significantly increase during the severe stage of the disease, including $\mathrm{C}$-reactive protein, ferritin, interleukin (IL)- $1 \beta$, IL-6, monocyte chemoattractant protein-1 (MCP-1), granulocyte colony-stimulating factor (G-CSF), C-X-C motif chemokine ligand-10 (CXCL-10), chemokine C-C motif ligand 3 (CCL3), tumor necrosis factor (TNF)- $\alpha$, and others [4]. Such excessive inflammation response has been described as a cytokine release syndrome, which appears to have led to acute lung 
injury/acute respiratory distress syndrome, multiple organ failure, and ultimately death [4]. Moreover, the immune response to the viral infection appears to have led to an overactivation of the coagulation pathways, which can further aggravate inflammation in a crosstalk that has substantially complicated the disease [5]. Together, coagulopathy and excessive inflammation appear to severely worsen the clinical outcomes of the viral infection, as demonstrated by the critically ill patients [5].

Considering the previous coronavirus outbreaks, i.e. severe acute respiratory syndrome coronavirus (SARS$\mathrm{CoV}$ ) [6] and Middle East respiratory syndrome coronavirus (MERS-CoV) [7], and the clinical presentations of the current outbreak, i.e. COVID-19 (also reported as SARSCoV-2) [8], treating severe coronavirus cases appears to need therapeutics possessing (1) antiviral activity to block any stage of the viral lifecycle; (2) anticoagulant activity to manage the patient's hypercoagulable state; and/or (3) antiinflammatory/immunomodulatory activity to mitigate the excessive inflammation. In this direction, factor Xa (FXa), a serine protease in the common coagulation pathway, is known to play a crucial role in coagulation by inducing the formation of thrombin, which eventually leads to the formation of cross-linked blood clots [9-11]. FXa has also been linked to inflammation [12] and viral infections [13]. In fact, direct FXa inhibitors have been reported to promote a host of pharmacological effects, including anticoagulant activity, anti-inflammatory activity, and antiviral activity (Fig. 1). Thus, direct FXa inhibitors may carry a significant therapeutic potential for coronavirus patients, particularly critically ill patients in the ongoing COVID-19 pandemic.

Currently, there are four clinically approved direct FXa inhibitors for use as anticoagulants, in addition to many others under investigation. The four approved FXa inhibitors are rivaroxaban (approved in 2011; Xarelto) [14], apixaban (2012; Eliquis) [15], edoxaban (2015; Savaysa) [16], and betrixaban (2017; Bevyxxa) [17]. The chemical structures of the four drugs are provided in Fig. 2. In the following sections, we briefly review the literature that supports the various pharmacological activities of direct FXa inhibitors so as to catalyze their use to combat the ongoing coronavirus pandemic.

\section{Anticoagulant Activity of Direct FXa Inhibitors}

Human FXa is a trypsin-like serine protease of the common coagulation pathway. Its zymogen, i.e. factor $\mathrm{X}$, is activated either via the intrinsic pathway (factor IXa) or the extrinsic pathway (factor VIIa/tissue factor) [9, 18]. FXa is the first serine protease in the common pathway leading to clot formation. The resulting FXa typically complexes with factor Va, calcium, and phospholipid to form prothrombinase, which subsequently activates prothrombin (also known as factor II) to thrombin (factor IIa) [19]. In turn, thrombin converts fibrinogen (factor I) to fibrin (factor Ia) monomers. Factor XIII, which is also activated by thrombin, converts the soluble fibrin monomers to insoluble cross-linked fibrin polymers on the surface of activated platelets, leading to the formation of a hemostatic plug [20]. Thrombin also positively feedbacks the cascade by activating factor XI [21], factor VIII [22] in the intrinsic pathway, and factor V [23] in the common pathway. This is to ensure the efficient generation of a burst of thrombin that amplifies and propagates the clotting response [24-27].
Fig. 1 Potential therapeutic benefits of direct FXa inhibitors in coronavirus infections. Four FXa inhibitors are approved anticoagulants, and several approved and experimental inhibitors have exhibited antiinflammatory and antiviral effects in different testing settings. $F X a$ factor $\mathrm{Xa}$

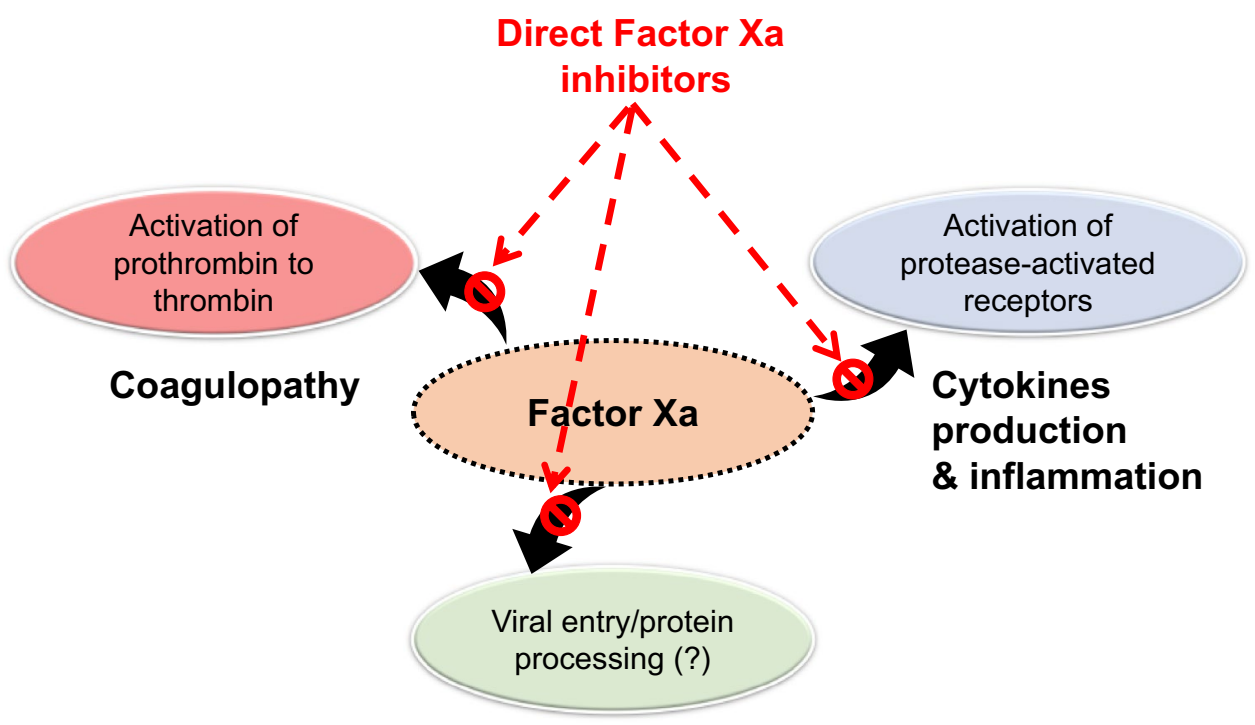

Viral infections 
<smiles>O=C(NC[C@H]1CN(c2ccc(N3CCOCC3=O)cc2)C(=O)O1)c1ccc(Cl)s1</smiles>

Rivaroxaban (2011, Xarelto)<smiles>CN1CCc2nc(C(=O)N[C@H]3CC[C@@H](C(=O)N(C)C)CC3NC(=O)C(=O)Nc3ccc(Cl)cn3)sc2C1</smiles>

Edoxaban

(2015, Savaysa)<smiles>COc1ccc(-n2nc(C(N)=O)c3c2C(=O)N(c2ccc(N4CCCCC4=O)cc2)CC3)cc1</smiles><smiles>COc1ccc(NC(=O)c2ccc(C(=N)N(C)C)cc2)c(C(=O)Nc2ccc(Cl)cn2)c1</smiles>

Fig. 2 Chemical structures of US FDA-approved direct FXa inhibitors, along with the year of FDA approval as well as their brand and generic names. $F X a$ factor $\mathrm{Xa}$

While the blood clotting process is important in maintaining hemostasis, its excessive activation typically leads to thrombotic complications. Moreover, activation of the coagulation cascade during viral infections is probably a protective mechanism to limit the spread of the infection. However, excessive clotting can lead to disseminated intravascular coagulation and subsequent hemorrhage. In fact, several reports have suggested that excessive coagulation is substantially linked to viral infections [28, 29] and, in this case, the viral infections by SARS-CoV-2, SARS-CoV-1, MERS-CoV [30]. Considering the ongoing pandemic, increasing evidence indicates that critically ill COVID-19 patients develop a hypercoagulable state that has been linked to poor outcomes of progressive respiratory failure and even death [31-36]. The hypercoagulable state of COVID-19 patients has been attributed to increased circulating prothrombotic factors, endothelial injury, and immobilization [37]. Disseminated intravascular coagulation, as well as coagulopathies of venous thromboembolism and ischemic stroke, has been described in severe cases of COVID-19 [37-41]. Interestingly, early anticoagulation in patients with severe COVID-19 infection has been found to reduce the risk of thrombotic complications and improve overall clinical outcomes, as was demonstrated by heparins, antithrombinbased anticoagulants [32, 35, 42-44].

Along these lines, direct FXa inhibitors are therapeutically approved for the prevention and/or treatment of venous thromboembolism, including deep vein thrombosis and pulmonary embolism [45, 46]. Mechanistically, the four approved drugs in Fig. 2 are small molecule, competitive, and highly selective inhibitors of the enzyme. In contrast to heparins, these inhibitors directly (without antithrombin) inhibit both the free FXa and the clot-bound FXa. Relative to other anticoagulant classes of warfarin, heparins, and direct thrombin inhibitors, direct FXa inhibitors are associated with relatively less internal bleeding risk [47, 48]. Needless to mention, there is a US FDA-approved antidote known as andexanet alfa $\left(\right.$ Andexxa $\left.{ }^{\circledR}\right)$ to treat potential bleeding events that may arise with their clinical use [49]. Importantly, FXa inhibitors are generally associated with less rebound hypercoagulation that is more common with heparins and direct thrombin inhibitors [50, 51]. In fact, while heparins appear to be gaining significant interest in treating COVID-19 patients [52,53], a recent study has documented evidence of heparin resistance in critically ill patients [54]. This suggests that alternative anticoagulants are in urgent 
need, and indeed, it encourages the consideration of direct FXa inhibitors.

Together, given the established efficacy and safety of direct FXa inhibitors as anticoagulants, and the pathogenesis of the ongoing viral pandemic, it is anticipated that these drugs can play a major role in treating the reported coagulopathies so as to mitigate the illness manifestations and reduce the death rate of COVID-19 patients.

\section{Anti-Inflammatory Activity of Direct FXa Inhibitors}

In addition to coagulation, human FXa also plays a substantial role in inflammation. In this arena, it was shown that FXa, via its interaction with effector cell protease receptor-1, may function as a mediator of acute inflammation in vivo. This pathway may augment both coagulation and inflammatory cascades and contribute to the pathogenesis of tissue injury [55]. It was also shown that exposing human umbilical vein endothelial cells to FXa concentration-dependently stimulated the cytokine production of IL-6, IL-8, and MCP-1, as well as the expression of adhesion molecules of E-selectin, intercellular adhesion molecule-1, and vascular cell adhesion molecule-1 [56]. The adhesion molecules also increased the polymorphonuclear leukocyte adhesion to the endothelial cells. To confirm the contribution of FXa, active site-blocked FXa was found inactive with respect to cytokine production and adhesion molecule expression [56]. FXa additively also contributed to the thrombin action of calcium-mobilizing and proinflammatory reactions of endothelial cells [57]. In fact, FXa was found to stimulate proinflammatory and profibrotic responses in fibroblasts [58], human atrial tissue [59], and RAW 264.7 macrophages [60] via protease-activated receptor- 2 . An investigational FXa inhibitor was also recently reported to inhibit MCP-1 production in endothelial cells via protease-activated receptor-1 [61]. As a result, FXa-mediated signaling has been implicated in the pathogenesis of several inflammatory diseases, including fibrosis, cardiovascular diseases, diabetic nephropathy, and cancer $[62,63]$.

Importantly, the anti-inflammatory effects of FXa inhibitors have been demonstrated in human subjects. For example, the anti-inflammatory effects of rivaroxaban and apixaban were recently observed in Japanese patients with atrial fibrillation [64]. The anti-inflammatory effect of apixaban was also recently demonstrated in the acute phase of ischemic stroke patients [65]. A post hoc analysis of the $\mathrm{X}$-VeRT trial also revealed that rivaroxaban caused a significant reduction in the levels of D-dimer and IL-6 in patients with atrial fibrillation [66]. These results indicate that blocking the activity of FXa may not only be beneficial to prevent the virus-associated coagulopathies but may also dampen the virus-triggered excessive immune response. In fact, it is plausible to assume that the current dosage regimens of the clinically available direct FXa inhibitors can be adequate to promote the much-needed anti-inflammatory activity to mitigate the cytokine storm of COVID-19, yet this remains to be properly evaluated in clinical trials.

\section{Antiviral Activity of Direct FXa Inhibitors}

SARS-CoV-2 is a single stranded, positive-sense RNA virus that utilizes a surface spike protein to enter the host cells, initially the epithelial cells of the respiratory system [67]. The spike protein has two important subunits linked together in the form of S1-S2. The S1 subunit carries the host receptor binding domain and the $\mathrm{S} 2$ subunit is responsible for the virus fusion with the host cell membrane. The $\mathrm{S} 1$ subunit of the viral spike protein binds to its receptor angiotensin-converting enzyme 2 (ACE2) on the host cell. A proteolytic activation mediated by the host proteases takes place to break the linkage between the S1 and S2 subunits so as to facilitate the virus fusion with the host cell membrane [67, 68]. Host proteases that are important for the activation process include furin, transmembrane protease serine 2 (TMPRSS2), and lysosomal cathepsins. Nevertheless, previous experience with SARS-CoV revealed that other host proteases may also be important for viral fusion and entry, including FXa [67, 68]. In fact, it was previously shown that an experimental FXa inhibitor blocked the viral entry of SARS-CoV into the host cells by preventing the spike protein cleavage into the $\mathrm{S} 1$ and $\mathrm{S} 2$ subunits. The inhibitor concentration-dependently blocked the SARS-CoV plaque formation in Vero E6 cells. Thus, direct FXa inhibitors may prevent coronavirus entry to human cells [69].

Furthermore, a recent study has computationally identified direct FXa inhibitors as potential inhibitors of TMPRSS2 [70]. In addition, another study suggested that FXa is essential for efficient replication of hepatitis E virus, a positive-stranded RNA virus, in cell culture and is potentially involved in ORF1 polyprotein processing [71]. Thus, direct FXa inhibitors may interfere with the replication of hepatitis E virus. Moreover, selective inhibition of FXa was recently shown to improve left ventricular function during coxsackievirus B3-induced myocarditis and appeared to lead to improved myocardial remodeling [72]. FXa inhibition also significantly reduced adeno-associated virus- 2 infections in mice [73]. Lastly, in human umbilical vein endothelial cells, FXa was also found to exploit herpes simplex virus-associated tissue factor to increase infection through cellular protease activated receptor-2, suggesting that FXa inhibitors will likely reduce viral infectivity [74]. Together, direct FXa inhibitors have been shown to promote a substantial (in)direct antiviral activity against a range of RNA 
and DNA viruses by blocking the viral entry stage [69] and possibly by other mechanisms [28, 70-74]. Such antiviral activity provides additional therapeutic benefit while using FXa inhibitors in COVID-19 patients.

\section{Pharmacokinetics, Drug-Drug Interactions, and Adverse Effects of Direct FXa Inhibitors}

All approved FXa inhibitors are orally used. With the exception of betrixaban, FXa inhibitors are hepatically metabolized to predominantly inactive metabolites. Renal elimination of rivaroxaban, apixaban, and edoxaban, and/or their metabolites, is significant. However, betrixaban is predominantly eliminated in feces [17]. Therefore, dose adjustment of rivaroxaban, apixaban, and edoxaban is needed in the case of renal impairment, while their use is to be avoided in patients with moderate or severe hepatic impairment. They all have moderate to high plasma protein binding profiles. This is of enormous significance in the case of rivaroxaban, which has the highest potential of plasma protein binding, and thus, should be cautiously used in COVID-19 patients with hypoalbuminemia [75]. The corresponding pharmacokinetic parameters of approved FXa inhibitors are listed in Table $1[14-17,76]$.

All FXa direct inhibitors are potentially associated with significant drug-drug interactions because they are metabolized by hepatic CYP450 enzymes (CYP450 3A4 for rivaroxaban, apixaban, and edoxaban) and/or they are substrates for p-glycoprotein [77]. With respect to their use in combination with currently used anti-COVID-19 therapeutics, recent analysis indicated that coadministration of rivaroxaban, apixaban, or edoxaban with lopinavir/ritonavir is associated with a high risk of serious drug-drug interactions that require dose adjustment. The same high risk exists between edoxaban and azithromycin [78]. The study also indicated mild or moderate potential interactions between rivaroxaban or apixaban and tocilizumab or sarilumab, as well as between edoxaban and hydroxychloroquine. A very low risk of drug-drug interactions is expected between direct FXa inhibitors and remdesivir, ribavirin, methylprednisolone, or anakinra [78].

The most common complication in using these drugs is bleeding, although bleeding risk may vary among the different agents. Reversing bleeding can be achieved by the use of andexanet alfa. If andexanet alfa is not available, four-factor prothrombin complex concentrate can be used $[79,80]$. Although andexanet alfa has not been evaluated to reverse the anticoagulant effects of betrixaban or edoxaban in humans, nevertheless, since both are similar FXa inhibitors as rivaroxaban and apixaban, it is likely that andexanet alfa will also be effective in reversing their actions [81].

\section{Conclusion}

Clinically available direct FXa inhibitors potentially hold a significant promise in treating COVID-19 because of their anticoagulant, anti-inflammatory, and antiviral activities. The diversity of their pharmacological effects will likely improve the overall clinical outcome of COVID-19 treatment. Currently, there are about 10 clinical studies that appear to include rivaroxaban, apixaban, or edoxaban in trials for COVID-19 patients (Table 2). Regarding the appropriate dosage regimens of FXa inhibitors to be used in COVID-19 patients, the reported protocols in the ongoing trials have considered dosage regimens similar to those being used in thrombotic patients, taking into account the status of their renal function. Some trials reported the drugs to be used for 21-30 days. Nevertheless, it remains to be determined whether the treatment protocols will yield the desired outcomes.

Importantly, an issue that may arise while using direct FXa inhibitors in treating hospitalized COVID-19 patients is the difficulty of administering oral solid pharmaceutical preparations, particularly to critically ill patients. However, this obstacle can potentially be overcome by the use of a crushed tablet in an aqueous suspension to be administered via nasogastric tube. In fact, a recent phase I, randomized,

Table 1 Pharmacokinetic profiles of direct FXa inhibitors

\begin{tabular}{|c|c|c|c|c|c|c|c|}
\hline Drug & Oral BA (\%) & $T_{\max }(\mathrm{h})$ & $V_{\mathrm{d}}$ & $t_{1 / 2}(\mathrm{~h})$ & $\begin{array}{l}\text { Protein bind- } \\
\text { ing }(\%)\end{array}$ & Metabolism & Excretion (\%) \\
\hline Rivaroxaban & $\begin{array}{l}80-100 \text { (food) } \\
\sim 60 \text { (fasting) }\end{array}$ & $2-4$ & $50 \mathrm{~L}$ & $\begin{array}{l}5-9 \\
11-13 \text { (elderly) }\end{array}$ & $\begin{array}{l}\text { 92-95 } \\
\quad \text { (albumin- } \\
\text { dependent) }\end{array}$ & $\begin{array}{l}\text { Hepatic CYP3A4/5 } \\
\text { and CYP2J2 }\end{array}$ & $\begin{array}{l}66 \text { (urine) } \\
28 \text { (feces) }\end{array}$ \\
\hline Apixaban & $\sim 50$ & $3-4$ & $21 \mathrm{~L}$ & $8-15$ & 87 & Hepatic CYP3A4/5 & 27 (urine) \\
\hline Edoxaban & & $621-2$ & $107 \mathrm{~L}$ & $10-14$ & 55 & Hepatic CYP3A4/5 & 50 (urine) \\
\hline Betrixaban & & $343-4$ & $32 \mathrm{~L} / \mathrm{kg}$ & $19-27$ & 60 & Minimal & 85 (feces) 11 (urine) \\
\hline
\end{tabular}

$B A$ bioavailability, $C Y P$ cytochrome $\mathrm{P} 450, F X a$ factor $\mathrm{Xa}$, $t_{1 / 2}$ terminal elimination half-life, $T_{\max }$ time to peak plasma concentration, $V_{d}$ apparent volume of distribution 


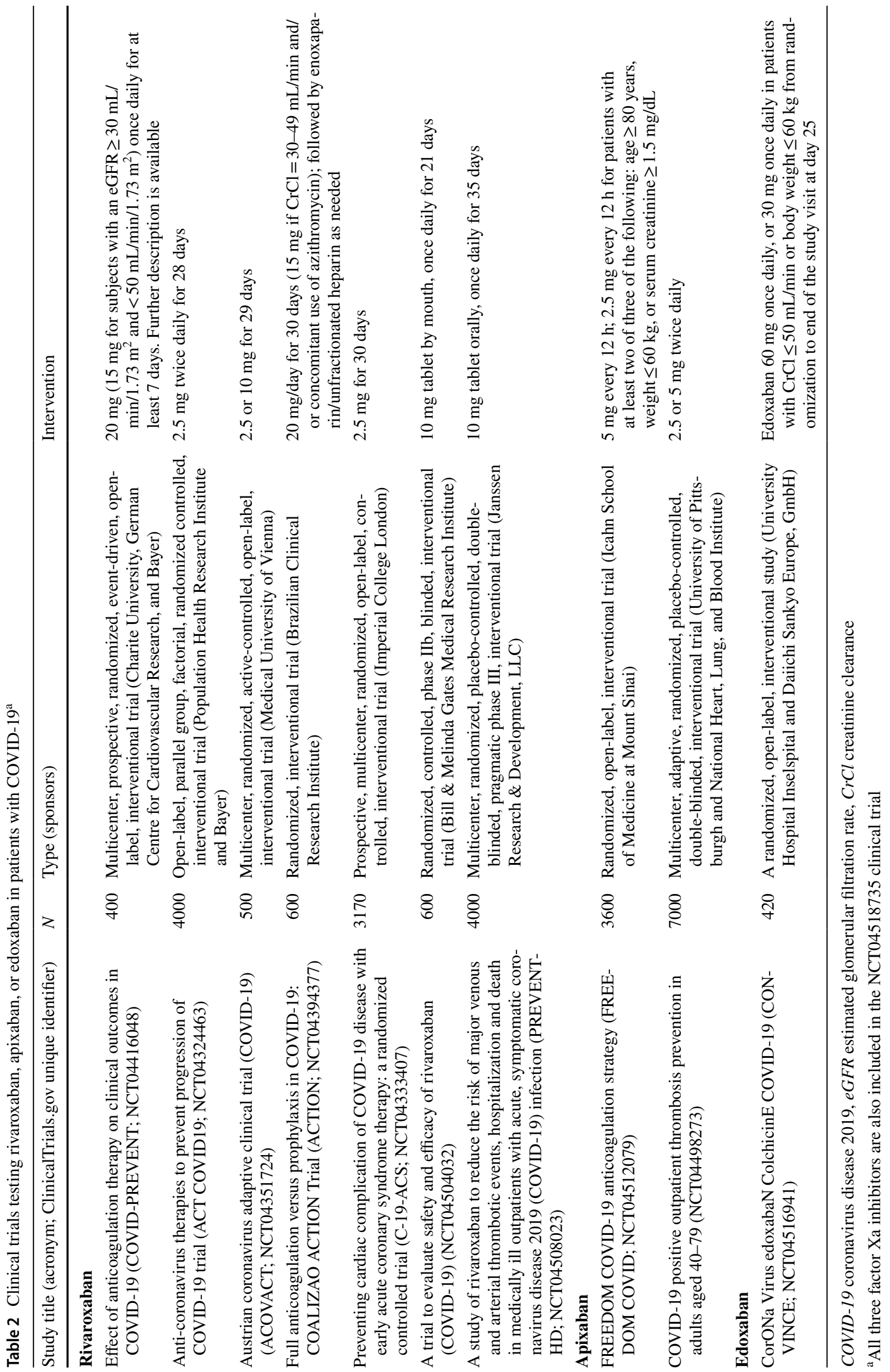


single-dose, crossover study presented results supporting the use of $60 \mathrm{mg}$ crushed edoxaban tablets for administration as an apple puree oral preparation or an aqueous suspension via a nasogastric tube [82]. One can be skeptical about the use of a nasogastric tube given the hemodynamic instability of critically ill patients. In this arena, betrixaban was approved for use in adult patients hospitalized for an acute medical illness who are at risk for thromboembolic complications because of moderate or severe restricted mobility and other risk factors for venous thromboembolism [83]. Overall, the development of a novel parenterally administered formulation or a parenteral delivery system for the currently available direct FXa inhibitors may further facilitate the realization of their full potential in treating hospitalized COVID-19 patients.

Acknowledgements Rami A. Al-Horani is supported by a grant from the National Institute of General Medical Sciences (NIGMS) under award number SC3GM131986. The content is the responsibility of the author and does not necessarily represent the official views of the National Institutes of Health.

\section{Declarations}

Conflicts of interest Rami A. Al-Horani declares no competing financial conflicts of interest.

\section{References}

1. Dong E, Du H, Gardner L. An interactive web-based dashboard to track COVID-19 in real time. Lancet Infect Dis. 2020;20(5):533-4.

2. The US Centers for Disease Control and Prevention. Coronavirus disease 2019 (COVID-19): people with certain medical conditions. https://www.cdc.gov/coronavirus/2019-ncov/need-extra -precautions/groups-at-higher-risk.html. Accessed 23 June 2020.

3. Demelo-Rodríguez P, Cervilla-Muñoz E, Ordieres-Ortega L, et al. Incidence of asymptomatic deep vein thrombosis in patients with COVID-19 pneumonia and elevated D-dimer levels. Thromb Res. 2020;192:23-6.

4. Jose RJ, Manuel A. COVID-19 cytokine storm: the interplay between inflammation and coagulation. Lancet Respir Med. 2020. https://doi.org/10.1016/s2213-2600(20)30216-2.

5. Esmon CT. The interactions between inflammation and coagulation. Br J Haematol. 2005;131(4):417-30.

6. Chan-Yeung M, Xu RH. SARS: epidemiology. Respirology. 2003;8(Suppl 1):S9-14.

7. de Groot RJ, Baker SC, Baric RS, et al. Middle East respiratory syndrome coronavirus (MERS-CoV): announcement of the Coronavirus Study Group. J Virol. 2013;87(14):7790-2.

8. Cucinotta D, Vanelli M. WHO declares COVID-19 a pandemic. Acta Biomed. 2020;91(1):157-60.

9. Yeh $\mathrm{CH}$, Fredenburgh JC, Weitz JI. Oral direct factor Xa inhibitors. Circ Res. 2012;111(8):1069-78.

10. Mackman N, Bergmeier W, Stouffer GA, Weitz JI. Therapeutic strategies for thrombosis: new targets and approaches. Nat Rev Drug Discov. 2020;19(5):333-52.

11. Rawlings ND, Salvesen G. Handbook of proteolytic enzymes. 3rd ed. Amsterdam: Elsevier; 2013.
12. Ruf W. FXa takes center stage in vascular inflammation. Blood. 2014;123(11):1630-1.

13. Pryzdial ELG, Sutherland MR, Lin BH, Horwitz M. Antiviral anticoagulation. Res Pract Thromb Haemost. 2020;4(5):774-88.

14. Mueck W, Eriksson BI, Bauer KA, Borris L, Dahl OE, Fisher WD, et al. Population pharmacokinetics and pharmacodynamics of rivaroxaban-an oral, direct factor Xa inhibitor-in patients undergoing major orthopaedic surgery. Clin Pharmacokinet. 2008;47(3):203-16.

15. Byon W, Garonzik S, Boyd RA, Frost CE. Apixaban: a clinical pharmacokinetic and pharmacodynamic review. Clin Pharmacokinet. 2019;58(10):1265-79.

16. Bounameaux A, Camm AJ. Edoxaban: an update on the new oral direct factor Xa inhibitor. Drugs. 2014;74(11):1209-31.

17. Garland SG, DeRemer CE, Smith SM, Gums JG. Betrixaban: a new oral factor Xa inhibitor for extended venous thromboembolism prophylaxis in high-risk hospitalized patients. Ann Pharmacother. 2018;52(6):554-61.

18. Smith SA, Travers RJ, Morrissey JH. How it all starts: initiation of the clotting cascade. Crit Rev Biochem Mol Biol. 2015;50(4):326-36.

19. Walker RK, Krishnaswamy S. The activation of prothrombin by the prothrombinase complex. The contribution of the substrate-membrane interaction to catalysis. J Biol Chem. 1994;269(44):27441-50.

20. Al-Horani RA, Kar S. Factor XIIIa inhibitors as potential novel drugs for venous thromboembolism. Eur J Med Chem. 2020;200:112442.

21. Mohammed BM, Matafonov A, Ivanov I, et al. An update on factor XI structure and function. Thromb Res. 2018;161:94-105.

22. Nogami K, Zhou Q, Wakabayashi H, Fay PJ. Thrombin-catalyzed activation of factor VIII with His substituted for Arg 372 at the P1 site. Blood. 2005;105(11):4362-8.

23. Dahlbäck B. Novel insights into the regulation of coagulation by factor $\mathrm{V}$ isoforms, tissue factor pathway inhibitor $\alpha$, and protein S. J Thromb Haemost. 2017;15(7):1241-50.

24. Green D. Coagulation cascade. Hemodial Int. 2006;10(Suppl 2):S2-4.

25. Davie EW, Fujikawa K, Kisiel W. The coagulation cascade: initiation, maintenance, and regulation. Biochemistry. 1991;30:10363-70.

26. Versteeg HH, Heemskerk JW, Levi M, et al. New fundamentals in hemostasis. Physiol Rev. 2013;93:327-58.

27. Vojacek JF. Should we replace the terms intrinsic and extrinsic coagulation pathways with tissue factor pathway? Clin Appl Thromb Hemost. 2017;23(8):922-7.

28. Antoniak S, Mackman N. Multiple roles of the coagulation protease cascade during virus infection. Blood. 2014;123(17):2605-13.

29. van Gorp EC, Suharti C, ten Cate H, et al. Review: infectious diseases and coagulation disorders. J Infect Dis. 1999;180(1):176-86.

30. Giannis D, Ziogas IA, Gianni P. Coagulation disorders in coronavirus infected patients: COVID-19, SARS-CoV-1, MERS-CoV and lessons from the past. J Clin Virol. 2020;127:104362.

31. Deng Y, Liu W, Liu K, et al. Clinical characteristics of fatal and recovered cases of coronavirus disease 2019 in Wuhan, China: a retrospective study. Chin Med J (Engl). 2020;133(11):1261-7.

32. $\mathrm{Li} \mathrm{T}, \mathrm{Lu} \mathrm{H}$, Zhang W. Clinical observation and management of COVID-19 patients. Emerg Microbes Infect. 2020;9:687-90.

33. Wu C, Chen X, Cai Y. Risk factors associated with acute respiratory distress syndrome and death in patients with coronavirus disease 2019 pneumonia in Wuhan, China. JAMA Intern Med. 2020;180(7):1-11.

34. Tang N, Bai H, Chen X. Anticoagulant treatment is associated with decreased mortality in severe coronavirus disease 2019 patients with coagulopathy. J Thromb Haemost. 2020;18:1094-9. 
35. Barrett CD, Moore HB, Yaffe MB. ISTH interim guidance on recognition and management of coagulopathy in COVID-19: a Comment. J Thromb Haemost. 2020;18(8):2060-3.

36. Ranucci M, Ballotta A, Di Dedda U, et al. The procoagulant pattern of patients with COVID-19 acute respiratory distress syndrome. J Thromb Haemost. 2020;18(7):1747-51.

37. Singhania N, Bansal S, Nimmatoori DP, Ejaz AA, McCullough PA, Singhania G. Current overview on hypercoagulability in COVID-19. Am J Cardiovasc Drugs. 2020. https://doi. org/10.1007/s40256-020-00431-z.

38. Oxley TJ, Mocco J, Majidi S, et al. Large-vessel stroke as a presenting feature of Covid-19 in the young. N Engl J Med. 2020;382(20): 660

39. Bompard F, Monnier H, Saab I, et al. Pulmonary embolism in patients with Covid-19 pneumonia. Eur Respir J. 2020;56(1):2001365.

40. Tang N, Li D, Wang X, Sun Z. Abnormal coagulation parameters are associated with poor prognosis in patients with novel coronavirus pneumonia. J Thromb Haemost. 2020;18(4):844-7.

41. Iba T, Levy JH, Levi M, Thachil J. Coagulopathy in COVID-19. J Thromb Haemost. 2020;18(9):2103-9.

42. Thachil J, Tang N, Gando S, et al. Type and dose of heparin in Covid-19: reply. J Thromb Haemost. 2020;18(8):2063-4.

43. Thachil J. The versatile heparin in COVID-19. J Thromb Haemost. 2020;18(5):1020-2.

44. Cattaneo M, Bertinato EM, Birocchi S. Pulmonary embolism or pulmonary thrombosis in COVID-19? Is the recommendation to use high-dose heparin for thromboprophylaxis justified? Thromb Haemost. 2020;120(8):1230-2

45. Kustos SA, Fasinu PS. Direct-acting oral anticoagulants and their reversal agents: an update. Medicines (Basel). 2019;6(4):103.

46. Al-Horani RA, Afosah DK. Recent advances in the discovery and development of factor XI/XIa inhibitors. Med Res Rev. 2018;38(6):1974-2023

47. Hellenbart EL, Faulkenberg KD, Finks SW. Evaluation of bleeding in patients receiving direct oral anticoagulants. Vasc Health Risk Manag. 2017;13:325-42.

48. Deitelzweig S, Farmer C, Luo X, Li X, Vo L, Mardekian J, et al. Comparison of major bleeding risk in patients with non-valvular atrial fibrillation receiving direct oral anticoagulants in the real-world setting: a network meta-analysis. Curr Med Res Opin. 2018;34(3):487-98.

49. Heo Young-A. Andexanet alfa: first global approval. Drugs. 2018;78(10):1049-55

50. Merlini PA, Ardissino D, Bauer KA, et al. Persistent thrombin generation during heparin therapy in patients with acute coronary syndromes. Arterioscler Thromb Vasc Biol. 1997;17(7):1325-30.

51. Ansell J. Factor Xa or thrombin: is factor Xa a better target? J Thromb Haemost. 2007;5(Suppl. 1):60-4.

52. Lindahl U, Li JP. Heparin - an old drug with multiple potential targets in Covid-19 therapy. J Thromb Haemost. 2020. https://doi. org/10.1111/jth.14898.

53. Belen-Apak FB, Sarialioglu F. The old but new: can unfractioned heparin and low molecular weight heparins inhibit proteolytic activation and cellular internalization of SARS-CoV2 by inhibition of host cell proteases? Med Hypotheses. 2020;142:109743.

54. White D, MacDonald S, Bull T, et al. Heparin resistance in COVID-19 patients in the intensive care unit. J Thromb Thrombolysis. 2020;50(2):287-91.

55. Cirino G, Cicala C, Bucci M, Sorrentino L, Ambrosini G, DeDominicis G, et al. Factor Xa as an interface between coagulation and inflammation. Molecular mimicry of factor Xa association with effector cell protease receptor-1 induces acute inflammation in vivo. J Clin Invest. 1997;99(10):2446-51.

56. Senden NH, Jeunhomme TM, Heemskerk JW, Wagenvoord R, van't Veer C, Hemker HC, et al. Factor Xa induces cytokine production and expression of adhesion molecules by human umbilical vein endothelial cells. J Immunol. 1998;161(8):4318-24.

57. Daubie V, Cauwenberghs S, Senden NH, Pochet R, Lindhout T, Buurman WA, et al. Factor Xa and thrombin evoke additive calcium and proinflammatory responses in endothelial cells subjected to coagulation. Biochim Biophys Acta. 2006;1763(8):860-9.

58. Borensztajn K, Stiekema J, Nijmeijer S, Reitsma PH, Peppelenbosch MP, Spek CA. Factor Xa stimulates proinflammatory and profibrotic responses in fibroblasts via protease-activated receptor-2 activation. Am J Pathol. 2008;172(2):309-20.

59. Bukowska A, Zacharias I, Weinert S, Skopp K, Hartmann C, Huth $\mathrm{C}$, Goette A. Coagulation factor Xa induces an inflammatory signalling by activation of protease-activated receptors in human atrial tissue. Eur J Pharmacol. 2013;718(1-3):114-23.

60. Zuo P, Zuo Z, Wang X, Chen L, Zheng Y, Ma G, Zhou Q. Factor Xa induces pro-inflammatory cytokine expression in RAW 264.7 macrophages via protease-activated receptor- 2 activation. Am J Transl Res. 2015;7(11):2326-34.

61. Shinozawa E, Nakayama M, Imura Y. TAK-442, a direct factor Xa inhibitor, inhibits monocyte chemoattractant protein 1 production in endothelial cells via involvement of protease-activated receptor 1. Front Pharmacol. 2018;9:1431.

62. Ebrahimi S, Rezaei S, Seiri P, Ryzhikov M, Hashemy SI, Hassanian SM. Factor Xa signaling contributes to the pathogenesis of inflammatory diseases. J Cell Physiol. 2017;232(8):1966-70.

63. Oe Y, Hayashi S, Fushima T, Sato E, Kisu K, Sato H, Ito S, Takahashi N. Coagulation factor Xa and protease-activated receptor 2 as novel therapeutic targets for diabetic nephropathy. Arterioscler Thromb Vasc Biol. 2016;36(8):1525-33.

64. Katoh H, Nozue T, Michishita I. Anti-inflammatory effect of factor-Xa inhibitors in Japanese patients with atrial fibrillation. Heart Vessels. 2017;32(9):1130-6.

65. Nakase T, Moroi J, Ishikawa T. Anti-inflammatory and antiplatelet effects of non-vitamin $\mathrm{K}$ antagonist oral anticoagulants in acute phase of ischemic stroke patients. Clin Transl Med. 2018;7(1):2.

66. Kirchhof P, Ezekowitz MD, Purmah Y, Schiffer S, Meng IL, Camm AJ, Hohnloser SH, Schulz A, Wosnitza M, Cappato $\mathrm{R}$. Effects of rivaroxaban on biomarkers of coagulation and inflammation: a post hoc analysis of the X-VeRT trial. H Open. 2020;4(1):e20-32.

67. Shang J, Wan Y, Luo C, Ye G, Geng Q, Auerbach A, Li F. Cell entry mechanisms of SARS-CoV-2. Proc Natl Acad Sci USA. 2020;117(21):11727-34.

68. Belouzard S, Chu VC, Whittaker GR. Activation of the SARS coronavirus spike protein via sequential proteolytic cleavage at two distinct sites Version 2. Proc Natl Acad Sci USA. 2009;106(14):5871-6.

69. Du L, Kao RY, Zhou Y, He Y, Zhao G, Wong C, Jiang S, Yuen $\mathrm{KY}$, Jin DY, Zheng BJ. Cleavage of spike protein of SARS coronavirus by protease factor $\mathrm{Xa}$ is associated with viral infectivity. Biochem Biophys Res Commun. 2007;359(1):174-9.

70. Kim J, Zhang J, Cha Y, et al. Advanced bioinformatics rapidly identifies existing therapeutics for patients with coronavirus disease-2019 (COVID-19). J Transl Med. 2020;18(1):257.

71. Kanade GD, Pingale KD, Karpe YA. Activities of thrombin and factor $\mathrm{Xa}$ are essential for replication of hepatitis $\mathrm{E}$ virus and are possibly implicated in ORF1 polyprotein processing. J Virol. 2018;92(6):e01853-17.

72. Malz R, Weithauser A, Tschöpe C, Schultheiss HP, Rauch U. Inhibition of coagulation factor Xa improves myocardial function during CVB3-induced myocarditis. Cardiovasc Ther. 2014;32(3):113-9.

73. Schuettrumpf J, Zou J, Zhang Y, Schlachterman A, Liu YL, Edmonson S, Xiao W, Arruda VR. The inhibitory effects of anticoagulation on in vivo gene transfer by adeno-associated viral or adenoviral vectors. Mol Ther. 2006;13(1):88-97. 
74. Sutherland MR, Ruf W, Pryzdial EL. Factor Xa and factor VIIa utilize herpes simplex virus-associated tissue factor to increase infection through cellular protease activated receptor 2 . Blood. 2009; 114(22):2130.

75. Huang J, Cheng A, Kumar R, Fang Y, Chen G, Zhu Y, Lin S. Hypoalbuminemia predicts the outcome of COVID-19 independent of age and co-morbidity. J Med Virol. 2020. https://doi. org/10.1002/jmv.26003.

76. Siddiqui F, Hoppensteadt D, Jeske W, Iqbal O, Tafur A, Fareed J. Factor Xa inhibitory profile of apixaban, betrixaban, edoxaban, and rivaroxaban does not fully reflect their biologic spectrum. Clin Appl Thromb Hemost. 2019;25:1076029619847524.

77. Di Minno A, Frigerio B, Spadarella G, et al. Old and new oral anticoagulants: food, herbal medicines and drug interactions. Blood Rev. 2017;31(4):193-203.

78. Bikdeli B, Madhavan MV, Gupta A, et al. Pharmacological agents targeting thrombo-inflammation in COVID-19: review and implications for future research. Thromb Haemost. 2020;120(7):1004-24.

79. Tellor KB, Barasch NS, Lee BM. Clinical experience reversing factor $\mathrm{Xa}$ inhibitors with four-factor prothrombin complex concentrate in a community hospital. Blood Transfus. 2018;16(4):382-6.

80. Shih AW, Crowther MA. Reversal of direct oral anticoagulants: a practical approach. Hematology Am Soc Hematol Educ Program. 2016;2016(1):612-9.

81. Tomaselli GF, Mahaffey KW, Cuker A, et al. 2017 ACC Expert Consensus Decision Pathway on Management of Bleeding in Patients on Oral Anticoagulants: a Report of the American College of Cardiology Task Force on Expert Consensus Decision Pathways. J Am Coll Cardiol. 2017;70(24):3042-67.

82. Duchin K, Duggal A, Atiee GJ, et al. An Open-Label Crossover Study of the Pharmacokinetics of the 60-mg Edoxaban Tablet Crushed and Administered Either by a Nasogastric Tube or in Apple Puree in Healthy Adults. Clin Pharmacokinet. 2018;57(2):221-8.

83. US FDA. FDA approved betrixaban (BEVYXXA, Portola) for the prophylaxis of venous thromboembolism (VTE) in adult patients. https://www.fda.gov/drugs/resources-information-approved-drugs /fda-approved-betrixaban-bevyxxa-portola-prophylaxis-venou s-thromboembolism-vte-adult-patients. Accessed 25 Aug 2020. 